\title{
Oralidade e Jmproviso em Marcelino Freire: Ritmo, Voz e Subjetividade na Leitura de Totonha
}

\author{
Orality and Improvisation in Marcelino Freire: RHythm, \\ Voice and Subjectivity in the Reading of Totonha
}

\section{Geruza Zelnys de ALMEIDA *}

Resumo: O artigo discute aspectos da oralidade, como ritmo e voz, presentes no conto Totonha, de Marcelino Freire, responsáveis pela construção da subjetividade na leitura da personagem Totonha. A análise aproxima literatura, filosofia e antropologia e amplia a ideia de leitura do mundo e do literário.

Palavras-chave: Oralidade; Voz; Ritmo; Marcelino Freire.

Abstract: This article discusses aspects of orality, as rhythm and voice, present in the story Totonha of Marcelino Freire, responsible for the construction of subjectivity in reading the character Totonha. The analysis closes literature, philosophy and anthropology; and extends the it idea of reading the world and the literary object.

Key-words: Orality; Voice; Rhythm; Marcelino Freire.

Pois não conhecemos antecipadamente nosso ritmo.

Passamos a vida a procurá-lo. (Henri Meschonnic)

Quase não mudo de roupa, quase não mudo de lugar. Sou sempre a mesma pessoa. Que voa. (Marcelino Freire)

\footnotetext{
* Doutoranda em Teoria Literária e Literatura Comparada pela USP. Mestre em Literatura e Crítica Literária pela PUC-SP. Contato: zelnys@hotmail.com.
} 
A presença da oralidade na literatura contemporânea tem requisitado atenção especial da crítica, já que a maleabilidade inerente à oralidade entra em sintonia com a literatura, "em sua vertente reflexiva, plurissignificativa, humanizadora e, por conseguinte, poética” (FERNANDES, 2007, p. 19). Para Ong (1998, p. 22), etimologicamente o "texto, cuja raiz significa tecer, é, em termos absolutos, mais compatível com a enunciação oral" do que com a escrita propriamente, por isso não vê a supremacia desta em relação àquela:

Todos os textos escritos devem, de algum modo, estar direta ou indiretamente relacionados ao mundo sonoro, habitat natural da linguagem, para comunicar seus significados [...] A expressão oral pode existir - e na maioria das vezes existiu - sem qualquer escrita; mas nunca a escrita sem a oralidade. (ONG, 1998, p. 16)

Refletindo sobre a oralidade e a cultura escrita, Ong (1998) observa que essas diferentes práticas acarretam diferentes formas de consciência e de representação psicológicas. Ao se referir à oralidade primária, o autor comenta sobre pessoas que não sabem ler nem escrever e que, por isso, contrariam o privilégio da visão, aprendendo de boca e ouvido, ou seja, ouvindo e repetindo, de forma a sujeitar as palavras à tessitura sonora organizada pelo ritmo, antíteses, aliterações, assonâncias e sintaxe.

Esses estudos recentes tentam, de alguma forma, responder à demanda do oral e avaliar a complexidade de um tema que não se esgota na simples oposição ao escrito. Pelo menos é o que pensa Meschonnic (2006) em sua clara recusa à tradicional dualidade que reina absoluta de Platão aos pós-estruturalistas. Embora Meschonnic (2006) não poupe Derrida de sua crítica à supremacia do signo, suas concepções se aparentam ao ler na divisão binária uma estrutura hierárquica na qual um termo comanda o outro do "alto" (DERRIDA, 2001). Neste caso, o domínio da escrita sobre a oralidade funda-se numa "posição" ocupada na sociedade letrada, servindo-lhe como instrumento de elitização. Daí Meschonnic (2006) propor a tripartição entre oral, falado e escrito, na qual oral e falado não se confundem, pois, se o falado pode ser imitado na escritura, a oralidade faz dela sua morada. 
É possível ouvir o eco dessas formulações no estudo de Piglia (1999), ao mencionar que, ao final do conto, sentimos como que "algo irrecuperável foi dito", ou ainda que "não é o narrador oral o que persiste no conto, mas a sombra daquele que o escuta". Frisam-se os termos "dito" e "escuta", que aqui não se ligam apenas à boca e orelha, já que estamos no domínio da leitura, mas ao ritmo do texto que embala o leitor e o torna cúmplice do seu movimento.

Assim, partindo do oral como movimento da escritura, realizando-se na rítmica da frase, Meschonnic convoca a pensar a oralidade como inscrição do sujeito, ou seja, como lugar privilegiado de sua "subjetividade-especificidade-historicidade". Esse sujeito constituído na oralidade será examinado no conto Totonha, de Marcelino Freire, autor expoente da literatura contemporânea, que não se priva de temas delicados como o preconceito social e racial. Ao contrário, são eles o húmus que vem fertilizando sua produção literária.

\section{0 ritmo e a rima}

Totonha é um dos dezesseis contos, indicados como cantos, do livro Contos Negreiros (2005), Prêmio Jabuti 2006, que apresenta, numa singular prosa poética, o marginalizado, seja ele pobre, negro, homossexual ou mulher. Em Totonha, no Canto XVI, quem fala é a personagem que o intitula e que configura uma tripla representação da exclusão: pobre, mulher e idosa.

Mais interessante, no entanto, é que o texto se desenvolve como diálogo, apesar de só lermos o discurso de Totonha. Porém, entrelaçado ao seu, há a presença de um discurso virtual, ao qual ela responde, promovendo a dialogia, ou seja, no seu discurso ouvem-se os ecos de "outros" pontos de vista confrontados no seu discurso: o da professora, o do governo, o dos habitantes do vale do Jequitinhonha e o da natureza. Essas vozes virtuais são postas em cheque numa construção que desconcerta o leitor porque quebra sua expectativa de certo e errado: Totonha se dirige à professora que, supostamente, quer ensiná-la a escrever seu nome, recusando a "ajuda".

Para isso, ela elabora o que se poderia chamar de um improviso. Chamo improviso o emaranhado de perguntas-respostas que a personagem constrói até chegar não a uma verdade, mas a um dilema 
que não pode ser resolvido no texto: "Eu é que não vou baixar minha cabeça para escrever. Ah, não vou” (a esse dilema pretendo voltar no decorrer do artigo).

O improviso seria, portanto, uma estratégia de construção menos racional do que sensível, pois faz uso dos recursos poéticos próprios da poesia: o ritmo, a entonação e a rima. Entretanto, a interpelação de Totonha ao leitor não clama à identificação, mas ao (re)conhecimento do seu lugar social, ou ainda, do ambiente ao redor: "Capim sabe ler? Escrever? Já viu cachorro letrado, científico? Já viu juízo de valor? Em quê? Não quero aprender, dispenso".

Nota-se que as perguntas que iniciam o texto não exigem respostas científicas. Exigem reflexão. São muito menos simples do que parecem a princípio: falam de natureza, ciência, valores e, ainda, desestabilizam o leitor letrado que se depara com uma personagem que lhe diz: não quero ser como você: "Não quero aprender, dispenso". $\mathrm{O}$ fato de a personagem dispensar o aprendizado força o leitor a despensar o que ele tem como verdade absoluta: o letramento/ alfabetização como valor positivo. Afinal, o confronto não se dá pelo que ela diz, mas pelo como diz, ou seja, por meio de um dizer específico que não fala sobre ela, mas é ela própria, sujeito incomunicávelcomunicável da linguagem:

O que ela [a linguagem] mostra melhor é o que você faz dela. Por isso somos todos, nós mesmos, inteiramente, o conteúdo da linguagem. A linguagem é, a cada vez, o sujeito inteiro. Sua história. Que significa mais o que ele não diz do que o que ele diz. O que interessa é descobrir como. O incomunicado é o que se comunica antes de tudo. (MESCHONNIC, 2006, p. 4)

Mas, onde então encontrar o sujeito em sua presença inapreensível na palavra? Meschonnic dirá que ele vive no ritmo: “o ritmo, que não está em nenhuma palavra separadamente mas em todas juntas, é o gosto do sentido. Sua física” (MESCHONNIC, 2006, p. 4). Daí a necessidade de reconhecer o movimento da fala na escritura, na rítmica da frase que, em Totonha, é marcada por frases curtas e repetições por reenvio ou retomada de termos que vão ampliando, imageticamente, os sentidos: 
Deixa pra gente que é moço. Gente que tem ainda vontade de doutorar. De falar bonito. De salvar vida de pobre. O pobre só precisa ser pobre. E mais nada precisa. Deixa eu, aqui no meu canto. Na boca do fogão é que fico. Tô bem. Já viu fogo ir atrás de sílaba?

Os elementos grifados sinalizam repetições, e estas marcam diferenças: o segundo gente restringe o primeiro; os de são cumulativos; o trio de pobre visa chegar à nulidade total através da abstração; o segundo precisa inverte o sentido do primeiro; na boca especifica meu canto; fogo retoma o derivado fogão. Essa linguagem imagética não precisa da ponderação que se espera no texto escrito: a remissão de fragmentos, muitas vezes realizada pela profusão de rimas no interior do texto, funciona como uma pintura, cujo jogo entre luz e sombra dirige sensivelmente os olhos a deslizarem pelos contornos do objeto.

Esse deslizamento, efeito e causa da oralidade, é fisicamente incorporado pelo leitor que traga essa linguagem que não é a sua, mas de um outro que o habita no momento da leitura e passa a controlar seus impulsos respiratórios. O ritmo está ligado à respiração e esta, por sua vez, mantém o vínculo entre o homem e seu exterior: quando cessa a respiração, cessa a vida. Assim, o leitor precisa ler Totonha, a personagem, aos solavancos, com seu imaginário respiratório, porque ela é esse sujeito que reúne e remenda as concepções suas às dos outros; o saber de um não-saber sabedor, porque poético. E,

[...] o poema não sabe mais. Não ensina um saber. Não ensina. Evidentemente. Mas ele mostra. Trabalha o insabido. Nem à margem, nem fora dela. Sua utopia é estar aqui. Seu partido, e também o da crítica, é o partido do ritmo. Sua política. (MESCHONNIC, 2006, p. 6)

Portanto, a movência do ritmo institui um sujeito político, pois, em interação com o entorno, que se ou(vê) dentro da escritura:

Se a escritura é o que acontece quando alguma coisa é feita na linguagem por um sujeito e que jamais havia sido feito assim até 
aquele momento, então a escritura participa do desconhecido. Ou seja, do ritmo. Ela começa aí onde cessa o saber. E como o saber é o presente do passado, poderíamos dizer que a escritura é o presente do futuro, o futuro no presente, no momento em que ela tem lugar. Por conseguinte, em certos casos, talvez para sempre, ela é um passado que continua a ter o futuro (Idem, p. 9)

Essa presentificação faz da escritura o lugar indiscutível da oralidade: é nela que o sujeito se manifesta em linguagem:

Para mim, a melhor sabedoria é olhar na cara da pessoa. No focinho de quem for. Não tenho medo de linguagem superior. Deus que me ensinou. Só quero que me deixem sozinha. Eu e minha língua, sim, que só passarinho entende, entende? (grifos meus)

O estar só implica estar colada à sua linguagem como num amálgama. Incompreensível, inaudita, incomunicável, uma vez que apenas o passarinho a entende. E o leitor? O leitor somente a entenderá por detrás de sua "linguagem superior", com a sabedoria do olhar para com o texto tátil-visual que esconde o canto dos pássaros.

Destaca-se também que, nos contos de Marcelino Freire, o sujeito não é representado de modo caricatural, como às vezes ocorre com autores que pretendem representar o falado no escrito. Totonha não é falada por Marcelino, o autor a apresenta no título pelo apelido com que é chamada pelos seus amigos, colocando-se no mesmo nível em que esses se encontram: "No papel, sou menos ninguém do que aqui, no Vale do Jequitinhonha. Pelo menos aqui todo mundo me conhece. Grita, apelida. Vem me chamar de Totonha”. Assim, Marcelino apenas re-posiciona, no centro do papel, a posicionalidade que a personagem já tem no seu ambiente social, mesmo que esse seja um lugar marginal. Entretanto, com Totonha ao centro, toda a fisicalidade do papel se transforma no Vale do Jequitinhonha, o qual o leitor é convidado a adentrar. 
Desse modo, pode-se dizer que é Totonha quem se fala por meio de uma "linguagem ordinária", ${ }^{1}$ aparentemente banal e "repleta de duplicidade, [é] fugidia, ardilosa como a razão" (MESCHONNIC, 2006, p. 12). É o que se exemplifica em: "Deixa eu, aqui no meu canto. Na boca do fogão é que fico. Tô bem. Já viu fogo ir atrás de sílaba?”. As marcas canto, boca, fogo remetem a uma linguagem muito mais ágrafa do que gráfica, uma linguagem elementar, original, de canto de/da boca, mas fundamentalmente histórica. Desligada da mítica da poesia, essa linguagem vem dela, mas já está historicizada pela escritura, faltalhe a ingenuidade primaveril que o senso comum não cansa de associar à poesia, pois

[...] a poesia, aquém e além da oposição entre o verso e a prosa, toma a linguagem ordinária e mostra que toda linguagem é ordinária, e que ela surge daí. Ela é o ato pelo qual o ordinário se descobre toda a linguagem. E é, então, através da poesia que não há mais linguagem ordinária. Descobri-lo para si mesma é o trabalho da escritura. (MESCHONNIC, 2006, p. 4)

Por tudo isso, creio que, se a escritura esconde o sujeito generalizando-o pela arbitrariedade do signo linguístico e do uso regrado dele, "que interpõe seus filtros" (ZUMTHOR, 1993, p. 109), é pela oralidade que o sujeito se desvela naquilo que lhe é único e irrepetível: sua forma específica de exteriorizar e interiorizar o "em torno". O ritmo, então, é a "organização subjetiva do discurso da ordem do contínuo, não do descontínuo do signo” (MESCHONNIC, 2006, p. 17) que se manifesta gestualmente promovendo a subjetividade na linguagem.

${ }^{1}$ Ao se referir a expressão "linguagem ordinária”, Meschonnic aponta: “À primeira vista, ela parece dupla, pelo menos. (...) Ela designa, indistintamente, a linguagem e uma relação com a linguagem, que se esconde por detrás de uma aparente evidência, como se o termo mostrasse, com toda transparência, a própria natureza da linguagem. Um estatuto e uma teoria. A expressão linguagem ordinária é, então, tanto mais perversa, e perniciosa, quanto mais simples parece. Ela implica uma atitude e uma história localizadas, e o próprio instrumentalismo a que ela se refere passa despercebido por detrás de sua banalidade" (2006, p. 12). 


\section{0 gesto e a voz}

Para entender a importância da gestualidade nos contos de Marcelino Freire, retomo a entrevista a Lima Trindade ${ }^{2}$, quando ao ser questionado sobre a impressão de que seus contos "nasceram para serem lidos em voz alta", Marcelino assim se manifesta:

Eu escrevo em voz alta, sim. Gosto da palavra falada. Como lhe disse, escrevo a partir de uma primeira frase que ouvi por aí. Não tenho história para contar. Tenho um som para rimar. Vou construindo a história a partir de um mote. O que faço é música, costumo dizer. Embolada. E eu comecei a minha trajetória escrevendo para teatro. Gosto muito do teatro. Quando escrevo, imagino sempre um ator em cena. Eu penso muito nisso. $\mathrm{Na}$ palavra lançada, dita para ser ouvida. E eu leio e releio muito o que escrevo. Em voz alta, pela casa. Quando algo não está claro, o ouvido denuncia. E aí eu mudo, modifico o parágrafo. Eu adoro ler os meus contos em público.

No balanço do autor, percebe-se a importância do som "de ouvido" dos seus textos e a gestualidade teatral que o produz. Zumthor (1993, p. 105) comenta que a leitura silenciosa e ocular substituiu a "leitura ruminativa", de articulação vocal, devido à multiplicação e à circulação de escritos. De fato, na infância da escritura, voz era sinônimo de fonia. Contudo, é importante destacar que não é somente como fonia e performance que a oralidade se concretiza nos textos do autor, mas, também na prosódia e sintaxe que dão certa "visão da voz".

Diz Meschonnic (2006, p. 47) que

Se o sentido está nas palavras, a significância no ritmo e na prosódia, a significação pode estar na voz. Pela voz, a significação precede o sentido, ela o porta. As palavras estão na voz. Como

\footnotetext{
${ }^{2}$ Disponível em: http://www.verbo21.com.br/index.php?Itemid=94\&id= 77\&option=com_content\&task=view
} 
a relação precede e traz consigo os termos. O que a entonação faz. Compreender, paradoxalmente, precede o sentido.

Desse modo, compreender a voz é compreender a significação antes mesmo de ela significar e, por isso, apreendê-la em sua inapreensibilidade. Afinal, uma vez realizada, a significação não é mais a mesma, pois entra no processo metalingüístico e infinito de tradução.

A voz, portanto, não é expressa pelas palavras, mas no como essas palavras se realizam no texto, ou seja, no ritmo e na entonação que recebem. Assim como "a pontuação na poética de um texto é seu gestual, sua oralidade” (Idem, p. 23-24), a entonação, dada a partir da pontuação, é uma marca da alteração e/ou perturbação emotiva da personagem:

Tem coisa mais bonita? A geografia do rio mesmo seco, mesmo esculhambado? O risco da poeira? O pó da água? Hein? O que eu vou fazer com essa cartilha? Número? Só para o prefeito dizer que valeu a pena o esforço? Tem esforço mais esforço que o meu esforço? Todo dia, há tanto tempo, nesse esquecimento. Acordando com o sol. Tem melhor bê-á-bá? Assoletrar se a chuva vem? Se não vem?

Morrer, já sei. Comer, também. De vez em quando, ir atrás de preá, caruá. Roer osso de tatu. Adivinhar quando a coceira é só uma coceira, não uma doença. Tenha santa paciência!

Não é preciso ler o fragmento em voz alta para sentir as nuances da voz: o falar espaçado da segunda frase estende-se no olhar físico ou imaginativo, aguçado pela pergunta antecedente, imbuindo-o de uma ternura que vai esmorecendo até o "Hein?", cujo sobressalto faz com que o tom aumente nas frases sequenciais. Destacam-se duas frases que recebem entonações peculiares na leitura: "Tem esforço mais esforço que o meu esforço?”, cuja leitura obriga a acentuar o segundo termo esforço porque reenvia ao primeiro, e o termo meu por anteceder uma nova repetição. A segunda frase em destaque é: “Tenha santa paciência!", que, por fechar uma série de desabafos, soa como uma explosão com acento nas sibilantes santa e ciência. 
Essas reflexões sugerem que a voz indicia o tipo de relação estabelecida entre a personagem e seus interlocutores e, pela forma como Totonha se dirige à professora, percebe-se que estão de frente uma para a outra. De acordo com Hall (1973), em seus estudos sobre a proxemística, essa seria a "distância social” (1,20 a 3,60m) e marca o limite da dominação. Nela, há uma sensação da presença corporal do outro, porém o olhar é fundamental para manter o contato, pois o toque é interditado, ou seja, "quando se deixa de manter o olhar da outra pessoa equivale a abandoná-la, o que faz a conversa cessar" (HALL, 1973, p. 191; tradução minha) ${ }^{3}$. Então, no conto, é certo que ambas se olham já que o diálogo se mantém a despeito da distância social.

Ademais, na distância social, a voz varia entre normal a um pouco mais alta, podendo ser ouvida num raio de seis metros, ou seja, a voz marginal de Totonha se desloca da periferia para o centro desse círculo compreendido pelo som. Segundo Ong (1998, p. 85-6), essa propriedade sonora supera a visual, pois enquanto "a vista isola; o som incorpora":

A visão chega a um ser humano de uma direção por vez: para olhar para um aposento ou uma paisagem, preciso girar meus olhos de um lado para outro. Quando ouço, no entanto, reúno o som ao mesmo tempo de qualquer direção, imediatamente: estou no centro do meu mundo auditivo, que me envolve, estabelecendo-me em uma espécie de âmago da sensação e da existência. Esse efeito de centramento do som é o que a reprodução sonora de alta-fidelidade explora com profunda sofisticação. Podemos mergulhar no ouvir, no som. Na visão, não há uma maneira análoga de mergulhar em si mesmo. Ao contrário da visão - o sentido da dissecação - o som é, desse modo, um sentido unificador. A propósito, um ideal visual típico é a clareza e a distinção. [...] O auditório ideal, por outro lado, é harmonia, é um colocar junto.

\footnotetext{
3 “... cuando se deja de mantener la mirada de la otra persona equivale a despedirla, lo que hace que la conversación se detenga".
} 
É possível ainda que Totonha esteja no ambiente de trabalho ou em casa: "Deixa eu, aqui no meu canto. Na boca do fogão é que fico", pois a proximidade permite que "uma delas continue fazendo seu trabalho na presença da outra sem que com isso se cometa uma grosseria" (HALL, 1973, p. 191; tradução minha)

Por outro lado, pode ser que ambas estejam sentadas, mas nada indicia que a professora esteja em pé frente à Totonha no trecho: "Não preciso ler, moça. A mocinha que aprenda. O doutor. O presidente [...]", pois Totonha inverte facilmente as posições de quem precisa aprender: a moça/mocinha/professora, como se se movimentasse livremente no espaço, afirmando-contrariando seu próprio dizer: "Quase não mudo de roupa, quase não mudo de lugar. Sou sempre a mesma pessoa. Que voa.”.

É interessante que, mesmo se Totonha estivesse em pé diante da professora sentada, ainda assim não conotaria dominação em seu discurso porque a voz do letrado, pelo status que ocupa na sociedade, possui força mesmo quando não pronunciada em palavras: "há voz no silêncio e silêncio na voz. Há sempre sentido. Ou, sobretudo, há significação. Pois, para a linguagem, não existe fora da linguagem. Os silêncios fazem parte dela. Aliás, nós os fazemos falar" (MESCHONNIC, 2006, p. 38).

Assim, se a voz e o ritmo são invisíveis, a energia que produzem torna a oralidade visualizável na escritura. Totonha, uma vez desmascarado o signo, realiza sua subjetividade tornando-se sujeitovoz ou voz-sujeito sendo que a posição desses termos são continuamente redefinidas: enquanto sujeito, Totonha é uma voz, enquanto voz, Totonha é um sujeito.

\section{$3 \mathrm{O}$ sujeito no interior do dilema}

Será que eu preciso mesmo garranchear meu nome? Desenhar só pra mocinha aí ficar contente? Dona professora, que valia tem o meu nome numa folha de papel, me diga honestamente.

\footnotetext{
4 “... una de ellas continue haciendo su trabajo en presencia de la outra sin que por ello se cometa uma grosería”.
} 
Coisa mais sem vida é um nome assim, sem gente. Quem está atrás do nome não conta?

Totonha não é uma personagem de fácil acesso, as questões que ela coloca são, no mínimo, desestabilizadoras do senso comum: qualquer leitor que se dispõe a ler esse ou qualquer conto, a priori é a favor de qualquer programa de letramento/alfabetização. Porém, lendo Totonha, a personagem, ele é obrigado a dispensar suas certezas, o que, é claro, não significa apenas concordar com ela, mas refletir e relativizar seus próprios pontos de vista.

Isso significa que Totonha nivela-se com o leitor e é ouvida porque no interior de sua linguagem ressoa também a voz do outro, apropriada e remodelada sem ingenuidade porque nenhuma apropriação representativa é inocente (MOREIRAS, 2001). Isso se comprova no fragmento acima. Segundo Zumthor (1973, p. 113), para a "massa dos iletrados, a letra traçada é uma coisa - significante da mesma condição que toda coisa criada - irrefutável, mas inacessível, quase imaterial, portadora de esperanças ou pavores mágicos”. Totonha, embora iletrada, não participa da mesma massa a qual se refere Zumthor, para ela o nome é apenas coisa, sem misticismo algum: sem vida porque sem gente, sem voz.

É preciso levar em conta que Zumthor se baseia na cultura medieval e Totonha vive num outro tempo-espaço, contemporâneo, de passagem da cultura logocêntrica para a imagocêntrica "ou de uma cultura literária para uma tecnocultura electrônica. À emergência, em suma, de uma nova ordem cultural polarizada já não no livro e na leitura, mas na televisão e no computador.” (DIAS, 1998, p. 15). Totonha pode não saber ler e escrever, mas nem por isso sabe menos, pois está "informada" dos acontecimentos. Assim, a personagem alia a informação recebida pelas mídias a seu conhecimento de mundo:

O governo me dê o dinheiro da feira. O dente o presidente. E o vale-doce e o vale-lingüiça. Quero ser bem ignorante. Aprender com o vento, ta me entendendo? Demente como um mosquito. $\mathrm{Na}$ bosta ali, da cabrita. Que ninguém respeita mais a bosta do que eu. A química. (grifos meus) 
Diferente daquele que ignora sua própria ignorância, Totonha sabe dela e sabe que apenas ignorando há a oportunidade de aprender com o que existe e, por isso, se respeita. Não seria exagero lembrar Sócrates aqui, afinal ele também não sabia. Portanto, é nessa relação com o saber-não-saber, inscrita no seu ritmo e voz, que Totonha vai se constituindo como sujeito político.

Porém, como definir esse sujeito que parece sujeitar-se a todas as mazelas de sua condição social? Seu direito à liberdade significa abandono do político ou a recusa à representação? Essas questões não se resolvem facilmente, ao contrário, elas colocam a personagem em estado de "suspensão", visto que construída na/pela oralidade é definitivamente inacabada. Esse inacabamento ocorre porque a voz é, sobretudo, loucura (MESCHONNIC, 2006, p. 49), daí entender o desejo de Totonha ser "demente como um mosquito", o que lembra o discurso da histeria em Lacan: a histérica como sujeito que questiona o outro é quem, de fato, conduz ao saber.

A profusão de perguntas desemboca na asserção final: "Eu é que não vou baixar minha cabeça para escrever. Ah, não vou.", sinalizando o grande dilema do texto. Uso o termo dilema como tradução do "double bind", de Derrida, sugerido por Evandro Nascimento, na leitura de uma situação que "impõe uma decisão impossível entre duas solicitações que aparentemente se excluem” (2001, p. 99). Assim, a situação proposta - baixar a cabeça para escrever - se bifurca em duas significações: a primeira que denuncia a libertação pela aprendizagem e, a segunda, a submissão ao que o governo espera dela.

Essa estrutura é construída por um olhar dissimétrico que olha para sua própria representação, por isso "o campo de visão que o olhar dissimétrico articula já é sempre desarticulado por ele" (MOREIRAS, 2001, p. 168). De modo que Totonha, por um lado, pode ser o "novo sujeito político", representante da multidão e "resultado histórico que não é nem produtor nem cidadão porque não está interessada em se reconstituir como sujeito" ((MOREIRAS, 2001, p. 155) e daí explica-se seu acomodamento à situação exposta. Mas, por outro, ao transpor a representação pré-concebida, Totonha se afirma como "palavra nova", ou como venho defendendo, inaudita: “do representado virá o que subverte a representação, mas apenas se a 
subversão não resultar em nova representação" ((MOREIRAS, 2001, p. 191). Nesse sentido, seu acomodamento daria lugar a uma atitude de resistência frente ao que o outro, representando o poder hegemônico - professora/governo/leitor - espera dela. Porém, nenhuma das posições efetivamente se firmam.

Esta hesitação, como os deslizamentos orais, é decisiva para manter a tensão no texto de Marcelino Freire deixando em suspenso uma significação que pudesse resolvê-la. Talvez essa seja a causa do "irrecuperável" (PIGLIA, 1999) ao fim do conto: porque a "negociação política e/ou crítica da alteridade incorpora necessariamente um elemento de imprevisilidade: a alteridade nunca é dominada ou mesmo contida exaustivamente por antecipação" (MOREIRAS, 2001, p. 160). Tudo isso justifica o que Meschonnic (2006, p. 7) propõe no início do livro: o ritmo como "missão do sujeito" e como "experimentação imprevisível da alteridade sobre a identidade"; a oralidade e o ritmo como "a matéria e a questão da modernidade".

Nesse movimento contínuo, do ritmo e da voz, que chama o leitor a fundir-se com seu tempo e espaço por meio do imaginário respiratório, Totonha constrói sua subjetividade e historicidade também no papel, que é de onde ela se faz ouvir.

\section{Anexo A: Totonha}

Capim sabe ler? Escrever? Já viu cachorro letrado, científico? Já viu juízo de valor? Em quê? Não quero aprender, dispenso.

Deixa pra gente que é moço. Gente que tem ainda vontade de doutorar. De falar bonito. De salvar vida de pobre. O pobre só precisa ser pobre. E mais nada precisa. Deixa eu, aqui no meu canto. Na boca do fogão é que fico. Tô bem. Já viu fogo ir atrás de sílaba?

O governo me dê o dinheiro da feira. O dente o presidente. E o vale-doce e o vale-lingüiça. Quero ser bem ignorante. Aprender com o vento, ta me entendendo? Demente como um mosquito. $\mathrm{Na}$ bosta ali, da cabrita. Que ninguém respeita mais a bosta do que eu. A química.

Tem coisa mais bonita? A geografia do rio mesmo seco, mesmo esculhambado? O risco da poeira? O pó da água? Hein? O que eu vou fazer com essa cartilha? Número? 
Só para o prefeito dizer que valeu a pena o esforço? Tem esforço mais esforço que o meu esforço? Todo dia, há tanto tempo, nesse esquecimento. Acordando com o sol. Tem melhor bê-á-bá? Assoletrar se a chuva vem? Se não vem?

Morrer, já sei. Comer, também. De vez em quando, ir atrás de preá, caruá. Roer osso de tatu. Adivinhar quando a coceira é só uma coceira, não uma doença. Tenha santa paciência!

Será que eu preciso mesmo garranchear meu nome? Desenhar só pra mocinha aí ficar contente? Dona professora, que valia tem o meu nome numa folha de papel, me diga honestamente. Coisa mais sem vida é um nome assim, sem gente. Quem está atrás do nome não conta?

No papel, sou menos ninguém do que aqui, no Vale do Jequitinhonha. Pelo menos aqui todo mundo me conhece. Grita, apelida. Vem me chamar de Totonha. Quase não mudo de roupa, quase não mudo de lugar. Sou sempre a mesma pessoa. Que voa.

Para mim, a melhor sabedoria é olhar na cara da pessoa. No focinho de quem for. Não tenho medo de linguagem superior. Deus que me ensinou. Só quero que me deixem sozinha. Eu e minha língua, sim, que só passarinho entende, entende?

Não preciso ler, moça. A mocinha que aprenda. O doutor. $\mathrm{O}$ presidente é que precisa saber o que assinou. Eu é que não vou baixar minha cabeça para escrever.

Ah, não vou.

[in: Contos Negreiros, Record, 2005.]

\section{Referências Bibliográficas}

DERRIDA, Jacques. Posições. Belo Horizonte: Autêntica, 2001.

DIAS, Sousa. "Esforços de guerra: pensamento, comunicação e resistência". In: Estética do conceito: A filosofia na era da comunicação. Coimbra: Editora Pé de Página, 1998, p. 5-27.

FERNANDES, Frederico. $A$ voz e o sentido: poesia oral em sintonia. São Paulo: UNESP, 2007. 
FREIRE, Marcelino. “Totonha”. In: Contos Negreiros. São Paulo: Record, 2005, p. 79-81.

HALL, Edward T. La dimensión oculta. Enfoque antropológico del uso del espacio. Madrid: Instituto de Estudios de administración Local, 1973.

LACAN, Jacques. Psicoses. Rio de Janeiro: Jorge Zahar Editor, 1988.

MESCHONNIC, Henri. Linguagem: ritmo e vida. Belo Horizonte: Fale/ UFMG, 2006.

MOREIRAS, Alberto. A exaustão da diferença. Belo Horizonte: Ed. UFMG, 2001.

NASCIMENTO, Evandro. Derrida e a literatura: "notas" de literatura e filosofia nos textos da desconstrução. Niterói: EdUFF, 1999.

ONG, Walter J. Oralidade e cultura escrita: a tecnologização da palavra. Campinas: Papirus, 1998.

PIGLIA, Ricardo. Formas breves. Buenos Aires: Temas Grupo Editorial, 1999.

ZUMTHOR, Paul. A letra e a voz: a literatura medieval. São Paulo: Cia das Letras, 1993. 